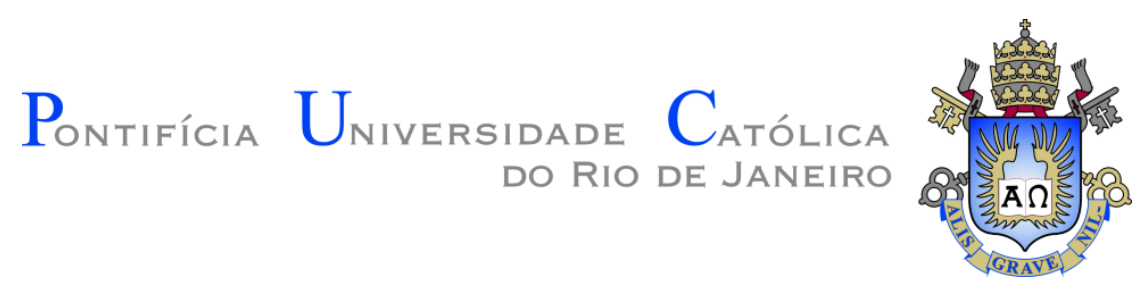

Yoanka Galcerán Chacón

\title{
Análise de um Compósito Pultrudado - Microscopia \\ Digital, Caracterização Mecânica e Envelhecimento
}

Tese de Doutorado

Tese apresentada como requisito parcial para obtenção do título de Doutor pelo Programa de Pós-Graduação em Engenharia de Materiais e de Processos Químicos e Metalúrgicos da PUC-Rio.

Orientadores:

Sidnei Paciornik

José Roberto Moraes d'Almeida

Rio de Janeiro, setembro de 2008 


\section{Análise de um Compósito Pultrudado - Microscopia \\ Digital, Caracterização Mecânica e Envelhecimento}

Tese apresentada como requisito parcial para obtenção do título de Doutor pelo Programa de PósGraduação em Engenharia de Materiais e de Processos Químicos e Metalúrgicos da PUC-Rio. Aprovada pela Comissão Examinadora abaixo assinada.

Prof. Sidnei Paciornik

Orientador

Departamento de Ciência dos Materiais e Metalurgia - PUC-Rio

Prof. José Roberto Moraes d'Almeida

Departamento de Ciência dos Materiais e Metalurgia - Co-Orientador PUC-Rio

Prof. Marcos Henrique de Pinho Mauricio Departamento de Ciência dos Materiais e Metalurgia - PUC-Rio

Prof. Roberto Ribeiro de Avillez Departamento de Ciência dos Materiais e Metalurgia - PUC-Rio

Profa. Veronica Maria de Araujo Calado Escola de Química - UFRJ

Profa. Lavínia Maria Sanabio Alves Borges

Engenharia Mecânica - UFRJ

Prof. José Eugênio Leal

Coordenador(a) Setorial do Centro Técnico Científico - PUC-Rio 
Todos os direitos reservados. É proibida a reprodução total ou parcial do trabalho sem autorização da universidade, da autora e do orientador.

\section{Yoanka Galcerán Chacón}

Engenheira Estrutural pelo Instituto Superior Técnico de Holguin/Cuba, Julho-1995. Mestre em Conservação e Reabilitação de Estruturas pelo Instituto Superior Politécnico J.A. Echeverría/Cuba, Junho-2003. Especialista em desenho estrutural e restauração de estruturas. Linhas de pesquisa: Caracterização Microestrutural de Materiais Compósitos, Correlação Microestrutura - Comportamento Mecânico de Materiais Compósitos, Microscopia Digital.

Ficha Catalográfica

\section{Galcerán Chacón, Yoanka}

Análise de um compósito pultrudado - microscopia digital, caracterização mecânica e envelhecimento / Yoanka Galcerán Chacón ; orientadores: Sidnei Paciornik, José Roberto Moraes d'Almeida. - 2008.

119 f. : il. (color.) ; $30 \mathrm{~cm}$

Tese (Doutorado em Engenharia de Materiais e de Processos Químicos e Metalúrgicos)-Pontifícia Universidade Católica do Rio de Janeiro, Rio de Janeiro, 2008.

Inclui bibliografia

1. Ciência dos Materiais e Metalurgia - Teses. 2. Compósito pultrudado. 3. Caracterização microestrutural. 4. Caracterização mecânica. 5. Microscopia digital. 6. Envelhecimento por UV. 7. Absorção de água. I. Paciornik, Sidnei. II. d'Almeida, José Roberto Moraes. III. Pontifícia Universidade Católica do Rio de Janeiro, Departamento de Ciência dos Materiais e Metalurgia. IV. Título. 
À minha família, meus maiores incentivadores, que ainda longe, tem participado junto comigo de todas as dificuldades e vitorias, com seu infinito amor, apoio e confiança.

Ao meu marido Leonardo, meu maior apoio e companheiro por todo o amor e carinho. Pela dedicação e valentia para recomeçar tudo de novo. 


\section{Agradecimentos}

À DEUS em primeiro lugar por ter me permitido cumprir com meus sonhos e com a confiança daqueles que sempre acreditaram em mim.

Ao Prof. Sidnei Paciornik, pelo extraordinário professor que foi ao longo da minha formação como estudante de doutorado. Pela orientação e por ter confiado que eu seria capaz de concluir esta etapa. Por ter convertido esse trabalho numa realidade.

Ao Prof. Marcos Henrique que sempre esteve disponível para me brindar seu apoio nas longas jornadas de trabalho.

Ao professor José Roberto d'Almeida por tudo o que aprendi, pela orientação e por ter ajudado e acreditado no êxito do trabalho.

Ao Departamento de Ciência dos Materiais e Metalurgia, seus professores, técnicos de Laboratório, secretárias e todo o pessoal que faz possível que cada dia de estudo e sacrifício seja justificado.

A meu professor em Cuba, Prof. Francisco Medina Torri de quem aprendi tudo o que me fez uma profissional melhor. 


\section{Resumo}

Chacón, Yoanka Galcerán; Paciornik, Sidnei; d'Almeida, José Roberto Moraes. Análise de um Compósito Pultrudado - Microscopia Digital, Caracterização Mecânica e Envelhecimento. Rio de Janeiro, 2008. 119p. Tese de Doutorado - Departamento de Ciência dos Materiais e Metalurgia, Pontifícia Universidade Católica do Rio de Janeiro.

Um compósito pultrudado de matriz polimérica reforçado por fibras de vidro foi caracterizado por microscopia digital, análise de imagens, ensaios mecânicos e envelhecimento por absorção de água e exposição a radiação ultravioleta (UV). A partir de uma placa do compósito, corpos de prova longitudinais e transversais foram obtidos e preparados para os diferentes experimentos. Mosaicos de imagens obtidas por Microscopia Eletrônica de Varredura (MEV), com alta resolução e grande abrangência espacial, foram automaticamente construídos e quantitativamente analisados. Foi desenvolvida uma metodologia de processamento e análise das imagens obtidas, permitindo obter, automaticamente, as frações de fibras, carga e matriz, do material, bem como a distribuição de tamanhos e formas das fibras. Os parâmetros microestruturais obtidos permitiram calcular propriedades mecânicas que foram comparadas com as obtidas diretamente de ensaios de flexão, com ótima concordância. O material foi envelhecido através da imersão em água e a mudança das propriedades mecânicas foi avaliada, indicando perdas significativas. A curva de absorção de água foi experimentalmente obtida e pode ser ajustada pelo modelo de Fick. A exposição a radiação UV não afetou as propriedades mecânicas dos compósitos quando os ensaios foram feitos na direção das fibras.Porém, quando os ensaios foram feitos na direção perpendicular às fibras houve uma queda consistente do módulo de elasticidade em função do tempo de exposição.

\section{Palavras-chave}

Compósito Pultrudado; Caracterização Microestrutural; Caracterização Mecânica; Microscopia Digital; Envelhecimento por UV; Absorção de água 


\section{Abstract}

Chacón, Yoanka Galcerán; Paciornik, Sidnei; d'Almeida, José Roberto Moraes. Analysis of a Pultruded Composite - Digital Microscopy, Mechanical Characterization and Aging. Rio de Janeiro, 2008. 119p. $\mathrm{Ph}$. D. Thesis - Departamento de Ciência dos Materiais e Metalurgia, Pontifícia Universidade Católica do Rio de Janeiro.

A glass fiber-reinforced polymer-matrix pultruded composite was characterized by digital microscopy, image analysis, mechanical tests, and aging by water absorption and UV exposure. Both longitudinal and transverse samples were obtained from a composite plate and prepared for the several experiments. Mosaics of images obtained by Scanning Electron Microscopy (SEM), with simultaneous high-resolution and wide spatial coverage, were automatically built and quantitatively analyzed. An image processing and analysis method was developed to obtain, in automatic fashion, the area fractions of fibers, filler and matrix, as well as the distribution of fiber sizes and shapes. The obtained microstructural measurements were used to estimate mechanical properties that were compared to those directly obtained from bending tests, with excellent agreement. The material was through immersion in water and the change in mechanical properties was evaluated, indicating significant losses. The water absorption curve was experimentally obtained and was fitted with the Fick model. Exposure to UV did not affect the mechanical properties when the tests were performed in the fiber direction. However, when tests were performed in a direction normal to the fibers, there was a consistent reduction of the Young modulus as a function of exposure time.

\section{Keywords}

Pultruded Composite; Microestrutural Characterization; Mechanical Characterization; Digital Microscopy; UV Aging; Water Absorption 


\section{Sumário}

1 INTRODUÇÃO 17

1.1. Considerações Gerais. $\quad 17$

1.2. Objetivo do trabalho. 19

1.3. Análise Microestrutural. Técnicas de Microscopia Eletrônica de Varredura e Processamento Digital de Imagens. 20

1.4. Análise do comportamento da resistência à flexão em três pontos. 21

1.5. Análise de Envelhecimento do material por absorção de água. 22

1.6. Análise de Envelhecimento do material por radiação ultravioleta. 25

1.7. Organização do Trabalho. 26

2 ANÁLISE DAS PROPRIEDADES DO MATERIAL ESTUDADO. 27

2.1. Considerações gerais. 27

2.2. Compósitos pultrudados reforçados com fibra de vidro e matriz polimérica.

2.3. Processo de pultrusão. 28

2.4. Constituintes do compósito pultrudado pesquisado. 31

2.4.1. Matriz polimérica termofixa: Resinas isoftálicas. 31

2.4.2. Fibras de vidro. 38

2.4.3. Aditivos. 42

2.5. Desempenho dos compósitos pultrudados. 44

3 PROCEDIMENTO EXPERIMENTAL. 48

3.1. Considerações gerais. 48

3.2. Compósito pultrudado empregado. 48

3.3. Caracterização Microestrutural. Análise Micromecânica. 50

3.3.1. Preparação das amostras. 50

3.3.2. Análise Microestrutural. Aplicação da Microscopia Eletrônica de Varredura (MEV) e Processamento Digital de Imagens (PDI). 51

3.4. Caracterização do comportamento macromecânico do material. 57 
3.4.1. Preparação das amostras.

3.4.2. Ensaio de resistência à flexão em três pontos. Determinação das propriedades mecânicas do material.

3.5. Ensaio de envelhecimento por absorção de água.

62

3.5.1. Ensaio de degradação por imersão em água destilada Preparação das amostras.

62

3.5.2. Ensaio mecânico do material degradado. Preparação das amostras.

3.6. Ensaio de envelhecimento pela exposição à radiação UV.

65

3.6.1. Preparação das amostras. Ciclos de exposição.

65

4 DISCUSSÃO DOS RESULTADOS EXPERIMENTAIS. 66

4.1. Resultados dos ensaios microestruturais. Análise e discussão. $\quad 66$

4.2. Análise Micromecânica.

73

4.3. Resultados do ensaio mecânico sem degradação. Análise e discussão.

4.3.1. Módulo de Elasticidade longitudinal e transversal.

4.3.2. Tensão de Flexão. Energia de Iniciação. 80

4.3.3. Limite de Resistência. Energia de propagação. 83

4.3.4. Tenacidade.

4.3.5. Análise comparativa do desempenho mecânico do compósito pultrudado não degradado, com os valores apresentados na bibliografia consultada.

4.4. Resultados do ensaio de degradação por absorção. Análise e discussão.

4.4.1. Ensaio de absorção. Curva de absorção. Ponto de saturação Coeficiente de difusão. Comparação com a bibliografia consultada.

4.4.2. Ensaio mecânico do material degradado por absorção de água. Propriedades mecânicas.

4.5. Resultados do ensaio de degradação por UV. Análise e discussão. 
6 REFERÊNCIAS BIBLIOGRÁFICAS.

7 ANEXO 1 - PROCEDIMENTO DE PREPARAÇÃO DE AMOSTRAS.

8 ANEXO 2 - IMAGENS DOS MOSAICOS TRANSVERSAIS.

9 ANEXO 3 - CURVAS TENSÃO-DEFORMAÇÃO: ENSAIO DE DEGRADAÇÃO POR ABSORÇÃO. 


\section{Lista de figuras}

Figura 1 - Esquema de classificação dos compósitos pela geometria da fase dispersa.

Figura 2 - Curvas tensão-deformação para compósito carbono-epóxi sob cargas transversais em condições de temperatura e umidade diferentes. [2,7].

Figura 3 - Estrutura padrão de um elemento pultrudado. Retirado de www.wpp.com.br (2005)

Figura 4 - Processo de pultrusão. Retirado de www.wpp.com.br (2005)

Figura 5 - Componentes básicos da máquina de pultrusão. Retirado www.wpp.com.br (2005)

Figura 6 - Poliéster insaturado 32

Figura 7 - Ácido Isoftálico

Figura 8 - Reação do poliéster insaturado com o monômero de estireno na obtenção da resina poliéster termofixa. 33

Figura 9 - Representação esquemática da resina isoftálica 35

Figura 10 - Gráficos comparativos de propriedades mecânicas especificas dos PRFV com as do aço e o concreto. 46

Figura 11 - Processo de produção do compósito pultrudado 49

Figura 12 - Placas de compósito pultrudado 49

Figura 13 - Esquema da distribuição e corte das placas de compósito pultrudado 49

Figura 14 - Análise Microestrutural. Amostra 1-Borda. Amostra 2-Centro 51

Figura 15 - Distribuição dos Mosaicos Transversais na largura da peça 52

Figura 16 - Imagem Mosaico com 18 campos do MEV, mostrando a variação da microestrutura ao longo da espessura da peça. Fibras aparecem brilhantes, carga e matriz em tons cinza e preto, respectivamente.

Figura 17 - Porção ampliada do mosaico da Figura 16 e seqüência do processamento da imagem na análise das fibras. (a) Imagem original. (b) Redução de ruído. (c) Imagem segmentada para fibras. 
(d) Eliminação de pequenos objetos. (e) Inversão. (f) Eliminação de buracos. (g) Imagem das fibras com objetos em contato. (h) Separação de objetos pelo método de separador de água. (i) Identificação das fibras. (j) Comparação com a imagem original.

Figura 18 - Distribuição dos corpos de prova do ensaio à flexão sem degradação no sentido longitudinal da peça.

Figura 19 - Dimensões dos corpos de prova e croqui do ensaio mecânico de flexão em três pontos (mm).

Figura 20 - Ensaio mecânico de flexão em três pontos do material não degradado na Máquina Universal INSTRON.

Figura 21 - Curva Carga versus Deslocamento no sentido paralelo às fibras.

Figura 22 - Curva Carga versus Deslocamento no sentido perpendicular às fibras.

Figura 23 - Trinca propagada na ruptura do espécime, orientação paralela às fibras.

Figura 24 - Trinca propagada na ruptura do espécime, orientação perpendicular às fibras.

Figura 25 - Corpos imersos em água destilada no processo de degradação por absorção

Figura 26 - Corpos imersos em água destilada no processo de degradação por absorção para o ensaio mecânico de flexão em três pontos

Figura 27 - Imagem com código de cores na detecção das fibras segundo critério de diâmetro.

Figura 28 - Imagem de detecção da fase carga.

Figura 29 -Comportamento da fração de área das fibras ao longo da largura das amostras.

Figura 30 - Curvas Tensão x Deformação no sentido longitudinal às fibras (L-1 a L-5).

Figura 31 - Comportamento do Módulo de Elasticidade ao longo da largura das amostras, no sentido paralelo às fibras.

Figura 32 - Curvas Tensão x Deformação no sentido transversal às fibras (T-1 a T-5).

Figura 33 - Análise do Módulo de Elasticidade no sentido transversal às 
fibras

Figura 34 - Energia de Iniciação no sentido longitudinal às fibras

(L-1 a L-5).

Figura 35 - Energia de Iniciação no sentido transversal às fibras

(T-1 a T-5).

Figura 36 - Energia de Propagação no sentido longitudinal às fibras

(L-1 a L-5).

Figura 37 - Energia de Propagação no sentido transversal às fibras

(T-1 a T-5).

Figura 38 - Gráfico da Tenacidade no sentido longitudinal às fibras

(L-1 a L-5).

Figura 39 - Gráfico da Tenacidade no sentido transversal às fibras

(T-1 a T-5).

Figura 40 - Gráfico comparativo da Resistência à flexão do compósito

estudado versus bibliografia consultada, no sentido longitudinal às fibras.

Figura 41 - Gráfico comparativo da Deformação do compósito estudado versus bibliografia consultada, no sentido longitudinal às fibras

Figura 42 - Gráfico comparativo do Módulo de Elasticidade do compósito estudado versus bibliografia consultada, no sentido transversal às fibras.

Figura 43 - Gráfico comparativo da Resistência máxima à flexão do compósito estudado versus bibliografia consultada, no sentido transversal às fibras

Figura 44 - Gráfico do incremento em peso por tempo de imersão. 94

Figura 45 - Curva de absorção teórica do material M\% versus Tempo $\left(\mathrm{h}^{1 / 2}\right)$. 95

Figura 46 - Curva Tensão x Deformação no sentido longitudinal às fibras

(AL-1 a AL-5). Material degradado por absorção para $\mathrm{t}=1440 \mathrm{~h}$.

Figura 47 - Curva Tensão x Deformação no sentido transversal às fibras

(AT-3 a AT-5). Material degradado por absorção para $\mathrm{t}=1440 \mathrm{~h}$.

Tabela 17 - Resumo das propriedades mecânicas na direção transversal às fibras. Material degradado por absorção para $\mathrm{t}=1440 \mathrm{~h}$.

Figura 48 - Gráficos comparativos dos valores médios do Módulo de 
Elasticidade do material degradado para $\mathrm{t}=0 \mathrm{~h}, 1440 \mathrm{~h}, 14208 \mathrm{~h}$ versus

bibliografia consultada, para compósito pultrudado ante e após da degradação.

Figura 49 - Gráficos comparativos dos valores médios da Tensão de Flexão do material degradado para $\mathrm{t}=0 \mathrm{~h}, 1440 \mathrm{~h}, 14208 \mathrm{~h}$ versus bibliografia consultada, para compósito pultrudado ante e após da degradação.

Figura 50 - Gráficos comparativos dos valores médios da Deformação do material degradado para $\mathrm{t}=0 \mathrm{~h}, 1440 \mathrm{~h}, 14208 \mathrm{~h}$ versus bibliografia consultada, para compósito pultrudado ante e após da degradação.

Figura 51 - Localização das amostras transversais e respectivas imagens em mosaico, para a amostra \#1.

Figura 52 - Localização das amostras transversais e respectivas imagens em mosaico, para a amostra \#2.

Figura 53 - Curvas Tensão-Deformação do ensaio de Flexão, após degradação por absorção de água. Sentido longitudinal (ALII 1 a 5). $\mathrm{t}=14208 \mathrm{~h}$.

Figura 54 - Curvas Tensão-Deformação do ensaio de Flexão, após degradação por absorção de água. Sentido transversal (ATII 1 a 5). $\mathrm{t}=14208 \mathrm{~h}$. 


\section{Lista de tabelas}

Tabela 1 - Fenômenos envolvidos na degradação dos plásticos reforçados. 36

Tabela 2 - Comparação de propriedades de resistência química de resinas isoftálicas, aço carbono, e aço inoxidável. 38

Tabela 3 - Propriedades da resina polimerizada não reforçada. 38

Tabela 4 - Composição aproximada de fibras de vidro tipo E. 40

Tabela 5 - Propriedades mecânicas de fibras de vidro tipo E. 40

Tabela 6 - Propriedades mecânicas e físicas em perfis pultrudados. 45

Tabela 7 - Redução das propriedades mecânicas em perfis pultrudados por efeito da temperatura. $\quad 47$

Tabela 8 - Peso seco dos corpos de prova testados por absorção de água destilada. 64

Tabela 9 - Arranjo das fibras em classes pelo diâmetro detectado nas imagens de mosaico. Amostra \#1.

Tabela 10 - Arranjo das fibras em classes pelo diâmetro detectado nas imagens de mosaico. Amostra \#2.

Tabela 11 - Resumo da fração de área de Fibras, Carga e Matriz nas amostras \#1 \& \# 2.

Tabela 12 - Resumo das propriedades mecânicas na direção paralela às fibras.

Tabela 13 - Resumo das propriedades mecânicas na direção perpendicular às fibras.

Tabela 14 - Parâmetros da absorção da água.

Tabela 15 - Tabela comparativa da absorção de água em 24 para o compósito estudado versus material de referência.

Tabela 16 - Resumo das propriedades mecânicas na direção paralela às fibras. Material degradado por absorção para $\mathrm{t}=1440 \mathrm{~h}$.

Tabela 18 - Resumo das propriedades mecânicas na direção paralelas às fibras. Material degradado por absorção para $\mathrm{t}=14208 \mathrm{~h}$

Tabela 19 - Resumo das propriedades mecânicas na direção transversal às 
fibras. Material degradado por absorção para $\mathrm{t}=14208 \mathrm{~h}$

Tabela 20 - Resumo comparativo dos valores meios das propriedades

mecânicas e porcentagem de variação, na direção paralela e

transversal às fibras antes e após da degradação.

Tabela 21 - Resumo das propriedades mecânicas na direção paralela às fibras. Material degradado por UV para $\mathrm{t}=576 \mathrm{~h}$.

Tabela 22 - Resumo das propriedades mecânicas na direção paralela às fibras. Material degradado por UV para $\mathrm{t}=1440 \mathrm{~h}$.

Tabela 23 - Resumo das propriedades mecânicas na direção paralela às fibras. Material degradado por UV para $\mathrm{t}=2160 \mathrm{~h}$.

Tabela 24 - Resumo comparativo dos valores meios das propriedades mecânicas e porcentagem de variação, na direção paralela às fibras antes e após da degradação por UV.

Tabela 25 - Resumo das propriedades mecânicas na direção transversal às fibras. Material degradado por UV para $\mathrm{t}=576 \mathrm{~h}$.

Tabela 26 - Resumo das propriedades mecânicas na direção transversal às fibras. Material degradado por UV para $\mathrm{t}=1440 \mathrm{~h}$.

Tabela 27 - Resumo das propriedades mecânicas na direção transversal às fibras. Material degradado por UV para $\mathrm{t}=2160 \mathrm{~h}$.

Tabela 28 - Resumo comparativo dos valores médios das propriedades mecânicas e porcentagem de variação, na direção transversal às fibras, antes e após da degradação por UV. 